\title{
Higienização das mãos: adesão da equipe multidisciplinar de saúde de um hospital ao norte do Estado de Minas Gerais
}

\author{
Écila Campos Mota*, Mirelle Gonçalves de Melo**, Viviane Ribeiro Barbosa**, Joanilva Ribeiro Lopes***, \\ Luís Paulo Souza e Souza****, Carla Silvana Oliveira e Silva*****, Diego Dias de Araújo ${ }^{* * * * * *}$
}

\begin{abstract}
*Enfermeira, Professora de Enfermagem das Faculdades Integradas Pitágoras de Montes Claros, das Faculdades Santo Agostinho e da Unimontes, Montes Claros, **Enfermeira graduada pelas Faculdades Santo Agostinho, ***Enfermeira, Professora de Enfermagem das Faculdades Santo Agostinho, ****Acadêmico do curso de Graduação em Enfermagem da Universidade Estadual de Montes Claros (Unimontes), ****Enfermeira, Professora de Enfermagem das Faculdades Santo Agostinho e da Unimontes, ***** Enfermeiro Residente Multiprofissional em Saúde do Idoso pelo Hospital das Clínicas da Universidade Federal de Minas Gerais
\end{abstract}

\section{Resumo}

Este estudo objetivou verificar a adesão da equipe multiprofissional de um Hospital ao norte do Estado de Minas Gerais quanto à higienização das mãos e em quais situaçôes é utilizada. Estudo quantitativo, descritivo e observacional. Foi utilizado um roteiro de observação previamente validado e testado pela Agência Nacional de Vigilância Sanitária para o registro das observaçôes. Foram observadas 85 oportunidades entre 15 profissionais de saúde, tendo $44 \%$ de adesão. Destaca-se a categoria médica pela baixa adesão, sendo que das 36 oportunidades de higienização das mãos, somente 4 oportunidades foram realizadas (11,2\%). Quanto à categoria de enfermagem, os técnicos obtiveram 35, com 62,8\% de adesão que equivale a 22 oportunidades realizadas; já os enfermeiros, das 14 oportunidades que tiveram, 12 foram concretizadas equivalendo a 85,8\% de adesão à higienização das mãos. A higienização das mãos em algumas indicaçôes não está incorporada à prática diária desses profissionais e, por isso, espera-se que as açôes educativas possibilitem a reflexão da atuaçáo de cada sujeito, propiciando a aprendizagem e modificando as práticas instituídas.

Palavras-chave: lavagem de mãos, controle de infecções, pessoal de saúde.

\section{Abstract \\ Hand hygiene: adherence of multidisciplinary health team of a hospital in the north of Minas Gerais}

This study aimed at verifying adherence of multiprofesional team of a hospital in the North Minas Gerais - Brazil regarding hand hygiene and when done correctly. This is a quantitative, descriptive and observational study. An observation guide previously validated and tested by the National Health Surveillance Agency to record the observations. 85 opportunities have been observed between 15 health professionals, with $44 \%$ of adherence. We observed low adhesion of medical professionals, as they had 36 hand hygiene opportunities and had only 4 hand washing were performed (11.2\%). Nursing professionals, 35 
nursing technicians had 22 opportunities and $62.8 \%$ of adherence; as regards to nurses, with 14 opportunities, 12 hand washing were performed $(85.8 \%)$. The hand hygiene in some occasions is not incorporated to daily practice of these professionals and, therefore, educational actions should be taken in order to provide learning and changing practices.

Key-words: hand washing, infection control, health personnel.

\section{Resumen}

\section{Higiene de las manos: adhesión del equipo multidisciplinario de la salud de un hospital en el norte del Estado de Minas Gerais}

Este estudio tiene como objetivo verificar la adhesión de equipo multidisciplinario de un hospital en el norte del Estado de Minas Gerais - Brasil relativo a la higiene de las manos y en qué situaciones es realizada correctamente. Estudio cuantitativo, descriptivo y observacional. Se utilizó un guion de observación previamente reconocidos y autorizados por la Agencia Nacional de Vigilancia Sanitaria para el registro de observaciones. 85 oportunidades han sido observadas entre 15 profesionales de la salud, con $44 \%$ de adhesión. Se destaca la categoría médica a la baja adhesión, puesto que en 36 oportunidades de higiene de manos, sólo 4 fueron realizadas (11,2\%). En relación a la categoría de Enfermería, 35 técnicos de enfermería tuvieron $62,8 \%$ de adhesión, o sea, 22 oportunidades realizadas; los enfermeros, 14 oportunidades y se realizaron 12 que equivale a 85,8\% de adhesión a la higiene de las manos. La higienización de las manos en algunas situaciones aún no está incorporada a la práctica diaria de estos profesionales y, por lo tanto, se espera que las acciones educativas permitan la reflexión de cada sujeto, propiciando el aprendizaje y cambio de las prácticas establecidas.

Palabras-clave: lavado de manos, control de infecciones, personal de salud.

\section{Introdução}

As infecçôes hospitalares ocorrem por diversas razóes e existem muitos mecanismos que favorecem seu aparecimento, um desses é a transmissão de microorganismos pelos profissionais da área de saúde, que atuam direta ou indiretamente na transmissão de microrganismo patogênico aos pacientes [1].

As infecçôes relacionadas à assistência à saúde representam atualmente uma preocupação não somente dos órgãos de saúde competentes, mas um problema de ordem social, ética e jurídica em face às implicaçóes na vida dos usuários e o risco a que estes estão submetidos. Essas infecções, além de acometerem clientes, ameaçam também profissionais da área de saúde, trabalhadores dos serviços de apoio, acompanhantes e demais usuários do serviço. O impacto das infecçóes relacionadas à assistência à saúde implica em prolongado período de internação hospitalar, aumento da resistência antimicrobiana, gastos excessivos para o sistema de saúde, pacientes e familiares e alta mortalidade [2].

A higienização das mãos é a maneira mais eficiente e econômica para a prevençáo de tais infecçóes nasocomiais e esse fato é mundialmente reconhecido. As máos são o principal meio de transmissão de infecçóes hospitalares e sua lavagem deve ser realizada antes e após qualquer procedimento empregado na assistência ao paciente [1].
Faz-se necessário descrever que a lavagem higiênica das mãos consiste no uso de água e sabão por um tempo de aproximadamente 30 segundos e é suficiente para a redução (>90\%) da microbiota transitória. Por outro lado, na remoçáo da microbiota normal deve ser considerada a utilização de formulaçóes contendo antissépticos. Na rotina diária de um profissional de saúde, há inúmeros procedimentos passíveis de contaminação das mãos, exigindo a higienização antes e após a sua execução [3].

A partir de estudos experimentais, em 1847, o médico húngaro Ignaz Philip Semmelweis, ao se deparar com os elevados índices de febre puerperal, postulou a interação entre lavagem das mãos e infecção hospitalar, de modo a instituir a obrigatoriedade da higiene das mãos com solução clorada entre o atendimento de cada paciente. Com esse procedimento, evidenciou-se a reduçáo drástica da taxa de mortalidade materna e comprovou que a higienização das mãos constitui medida primária para a prevenção das infecçóes hospitalares, uma vez que se caracteriza como principal ferramenta de transmissáo dos micro-organismos. Contudo, a falta de adesão dos profissionais de saúde a essa prática acarreta a necessidade de reformulação cultural, a fim de valorizar a segurança e a qualidade da assistência [4].

No anexo IV da portaria 2616/98, a higienização das mãos é, isoladamente, a ação mais importante para a prevençáo e controle das infecçóes hospitalares; 
a higienização das mãos deve ser realizada tantas vezes quanto necessária, durante a assistência a um único paciente, sempre que envolve contato com diversos sítios corporais e entre cada uma das atividades [5].

Devem ser empregadas medidas e recursos com os objetivos de incorporar a prática da higienização das mãos em todos os níveis de assistência hospitalar. A distribuição e a localização de pias para a higienização das máos de forma a atender à necessidade nas diversas áreas hospitalares, além da presença de produtos, são fundamentais para a obrigatoriedade da prática [2].

A importância da prática de higienização das mãos é baseada na capacidade de abrigar micro-organismos e transferi-los de uma superfície para outra, por contato direto, pele a pele, ou indireto por meio de objetos. $\mathrm{O}$ controle dessas infecçóes por meio da higienização cuidadosa e frequente das mãos atende às exigências legais e éticas, promove a segurança e a qualidade da atenção prestada ao cliente. Apesar de a transmissáo de infecçóes relacionada à assistência à saúde pelo contato das mãos ser admitida mundialmente e sua efetividade comprovada, o cumprimento das normas técnicas para sua prevenção é insatisfatório [2].

A adesão a essa medida tem-se constituído em um dos maiores desafios para as Comissóes de Controle de Infecçáo Hospitalar - CCIH que, dentre outros aspectos, envolve os recursos humanos nos estabelecimentos de saúde, seu preparo e sua conscientização. Frequentemente, as infecçóes hospitalares são associadas à baixa adesão dos profissionais da área da saúde à higienização das mãos [6].

Os profissionais que trabalham nas instituiçóes de saúde necessitam conhecer a verdadeira importância da correta higienizaçáo das máos, sendo que esta medida está relacionada com as boas práticas de higiene do ambiente que possibilitam ao paciente proteçáo contra infecçóes durante todo o período de internação. A maioria dos profissionais de saúde lavam as máos de maneira corriqueira, como a desenvolvem no dia a dia em suas residências, ou seja, como se não estivessem em âmbito hospitalar, dando, então, menor ênfase a essa medida tão necessária [7] .

Devido à longa jornada de trabalho, a equipe de saúde multiprofissional normalmente apresenta também um grande volume de atividades a serem realizadas. Assim, não é incomum observar a realização da técnica de higienização das mãos de forma rápida e desatenta, o que pode aumentar a incidência no quadro de infecções hospitalares, principalmente para os profissionais que prestam atendimento a pacientes mais vulneráveis. Como no século passado, os profissionais de saúde ainda necessitam ser lembrados constantemente de lavar suas máos durante o contato com o paciente [7].

De acordo com a Agência Nacional de Vigilância Sanitária (ANVISA), devem higienizar as mãos todos os profissionais que trabalham em serviços de saúde. Recomenda-se, ainda, que familiares, acompanhantes e visitantes higienizem as mãos antes e após terem contato com os pacientes nos serviços de saúde [8].

A higienização das mãos dos profissionais que atuam em serviços de saúde pode ser realizada utilizando-se água e sabão, preparaçôes alcoólicas e antissépticas degermantes. Dependendo do objetivo ao qual se destinam, as técnicas de higienização das máos podem ser divididas em higienização simples, higienização antisséptica, fricção de antissépticos, antissepsia cirúrgica ou preparo pré-operatório [8].

A eficácia da higienização das mãos depende da duração e da técnica empregada. Antes de iniciar qualquer uma dessas técnicas, é necessário retirar anéis, pulseiras e relógios, pois tais objetos podem acumular micro-organismos. Devem ser seguidas também algumas recomendaçôes, como: manter as unhas naturais, limpas e curtas, não usar unhas postiças, quando entrar em contato direto com os pacientes, evitar o uso de esmaltes nas unhas, aplicar creme hidratante nas máos (uso individual), diariamente, para evitar ressecamento da pele [8].

A higienizaçáo das mãos é, sem dúvida, um tema que pode se tornar constrangedor quando abordado diretamente, pois é difícil para um profissional de saúde assumir que falha em um aspecto tão fundamental. Sendo assim, são necessários estudos observacionais que busquem informaçóes mais fidedignas possíveis quanto ao hábito de higienizar as mãos [9].

Deve-se entender a importância da higienização das mãos e que a realizaçáo incorreta ou a não realização desse procedimento traz implicaçóes para as instituiçóes, profissionais e pacientes. $\mathrm{O}$ estudo teve como objetivo verificar a adesão da equipe multiprofissional quanto à higienização das mãos e em quais situações essa prática é utilizada.

\section{Material e métodos}

Trata-se de estudo quantitativo, descritivo e observacional, realizado no hospital Municipal São Vicente de Paulo do Município de Coração de Jesus, localizado ao norte de Minas Gerais. 
Para a coleta de dados foi utilizado um roteiro de observação previamente validado e testado pela Anvisa para o registro das observaçóes. Nesse instrumento constaram as oportunidades para a higienização das mãos, os tipos de higienização das mãos e as indicaçóes para essa prática. $\mathrm{O}$ estudo foi realizado no ambiente hospitalar, com todos os profissionais da equipe de saúde que exerceram suas atividades nos turnos matutinos e vespertinos, durante o período da coleta de dados que ocorreu no primeiro semestre de 2011, totalizando 15 profissionais.

A pesquisa foi embasada nas orientaçóes da Resolução do Conselho Nacional de Saúde no. 196/96, que estabelece as diretrizes de pesquisa que envolve seres humanos. Ressalta-se que o presente estudo foi aprovado pelo Comitê de Ética em Pesquisa das Faculdades Unidas do Norte de Minas (FUNORTE), sendo aprovado por meio do parecer consubstanciado número 030/11.

\section{Resultados e discussão}

Quinze profissionais foram observados (03 enfermeiros, 02 médicos e 10 técnicos de enfermagem), sendo identificadas, ao todo, 85 oportunidades de higienização das mãos, conforme pode ser observado na Tabela I.

Entende-se por oportunidades os momentos em que a higienização das mãos era necessária el ou recomendada, do ponto de vista do controle de infecção. No total, os médicos tiveram 36 oportunidades de higienização das mãos, os enfermeiros 14 oportunidades, já os técnicos de enfermagem tiveram 35 oportunidades.

Dentre as categorias profissionais que obtiveram mais oportunidades de higienização das mãos, estão os médicos, técnicos de enfermagem e, por último, os enfermeiros. Dessas, destaca-se a categoria médica pela baixa adesão, sendo que, das 36 oportunidades de higienizaçáo das máos, somente 4 oportunidades foram aproveitadas (11,2\%). Quanto à categoria de enfermagem, incluindo os técnicos e os enfermeiros, somam-se 49 oportunidades de higienização das mãos. Destas 49 oportunidades, os técnicos tiveram 35 oportunidades de higienizar as mãos, ficando com $62,9 \%$ de adesáo, que equivale a 22 oportunidades aceitas.

Já os enfermeiros tiveram menos oportunidades, devido à sobrecarga dos serviços administrativos e não estarem tão presentes ao serviço prático, tendo, assim, 16,5\% de todas as oportunidades ocorridas, ou seja, 14 oportunidades e, destas, 12 foram realizadas, equivalendo a $85,8 \%$.

Os fatores que buscam explicar a baixa adesão às práticas de higienização das mãos são atualmente conhecidos graças a estudos observacionais, de intervenção ou de inquéritos epidemiológicos, nos quais os profissionais de saúde apontam as razóes de não seguirem as recomendações [8].

Mas, uma questáo a ser analisada é o comportamento humano, que pode variar, caso o profissional saiba que está sendo observado. Nesse caso, sua atitude em relação à higienização das mãos pode mudar, no sentido de aumentar a adesão nos períodos que estáo sendo observados [10].

Autores realizaram um estudo relevante, observando 2.834 oportunidades para higienização simples das mãos com água e sabonete, e identificaram 48\% de adesão. $\mathrm{Na}$ análise multivariada, a adesão foi maior entre enfermeiros, durante os dias da semana, em comparação com outras categorias profissionais [9].

O fato de ser médico é associado à baixa adesão à higienização das mãos e varia de acordo com a especialidade. Em estudo realizado, observando a adesão à higienização das mãos entre médicos, a taxa global de adesão foi de $57 \%$, variando de $23 \%$ entre os anestesiologistas a $87 \%$ entre os clínicos [9].

Neste estudo, os médicos também obtiveram baixa adesão à higienização das mãos. É importante ressaltar que o Hospital Municipal Sáo Vicente de

Tabela I - Adesão à higienização das mãos, segundo número de oportunidades para essa prática pelos profissionais do Hospital Municipal São Vicente de Paulo - Coração de Jesus, 2011.

\begin{tabular}{|c|c|c|c|c|c|c|}
\hline \multirow[t]{2}{*}{ Categoria profissional } & \multirow{2}{*}{$\begin{array}{c}\text { Número de opor- } \\
\text { tunidades }\end{array}$} & \multicolumn{2}{|c|}{$\begin{array}{l}\text { Adesão } \\
\text { (Sim) }\end{array}$} & \multicolumn{2}{|c|}{$\begin{array}{l}\text { Adesão } \\
\text { (Não) }\end{array}$} & \multirow[t]{2}{*}{ Total } \\
\hline & & $\mathrm{n}$ & $\%$ & $\mathrm{n}$ & $\%$ & \\
\hline Enfermeiro & 14 & 12 & 85,8 & 02 & 14,2 & 100 \\
\hline Médico & 36 & 04 & 11,2 & 32 & 88,8 & 100 \\
\hline Técnico de enfermagem & 35 & 22 & 62,9 & 13 & 37,1 & 100 \\
\hline Total & 85 & 38 & & 47 & & 100 \\
\hline
\end{tabular}

Fonte: Coleta de dados, 2011. 
Paulo é de pequeno porte e possui infraestrutura inadequada, por exemplo: número de pias insuficientes e posicionadas incorretamente, e falta de sabão líquido e álcool gel a 70\% nos dispensadores, o que pode ter influenciado a baixa adesáo.

Em alguns hospitais brasileiros, observam-se problemas relacionados à falta de pias, ou pias em número insuficiente, como também a ausência de dispensadores para sabão, fazendo-se necessária a utilização de antissépticos [2].

Atualmente, o álcool em gel a $70 \%$ é citado na literatura como uma forma de aumentar a adesão dos profissionais de saúde à higienização das mãos e diminuir a taxa de infecçóes relacionadas à assistência à saúde, pois se gasta menos tempo para a realizaçáo dessa prática e o produto age mais rápido e é eficaz na redução da carga microbiana [2].

A Anvisa lançou, em 2007, uma cartilha de higienização das mãos em serviço de saúde que é distribuída a instituiçóes de todo o país. Além disso, foi aprovada uma resoluçáo que obriga os serviços a disponibilizar álcool em gel em torno dos ambientes onde ocorrem procedimentos com paciente.

Para a apresentação dos dados em relação às açóes e indicaçóes segundo a categoria profissional foi construída uma tabela de acordo com o formulário de observação. São priorizadas cinco indicações: antes de contato com paciente, antes de realizar procedimentos assépticos, após risco de exposição a fluidos corporais, após contato com paciente, após contato com superfícies e objetos próximos ao paciente (Tabela II).
Dos 85 registros de oportunidade de higienização das mãos, a adesão foi 38 (44,7\%), considerando o uso de álcool a $70 \%$ e água e sabão. Desses registros, 17 (44,7\%) foram fricção com álcool a $70 \%$ e $21(55,3 \%)$ de higienização das máos com água e sabão.

Como se observa na Tabela II, em todas as indicações, os médicos obtiveram 19\% de adesão com água e sabão e nenhuma com álcool a 70\%; os enfermeiros tiveram adesão de $28,6 \%$ com água e sabão e $35,2 \%$ com álcool a $70 \%$. Os técnicos de enfermagem aderiram $52,4 \%$ com água e sabão e 64,7\% com álcool.

Os dados mostram em quais situações os profissionais mais aderem à higienização das mãos. Dessas, a que houve menor adesáo foi antes do contato com o paciente, pois $80,8 \%$ das oportunidades não foram realizadas, apenas $11,5 \%$ foram realizadas com água e sabão, 7,7\% com fricção alcoólica. A indicação após contato com paciente foi a segunda de menor adesão com $(18,9 \%)$ com água e sabão, $(21,6 \%)$ fricçáo com álcool e $(59,5 \%)$ não aproveitadas.

Podemos observar que a prática da higienização das mãos foi mais utilizada na realização de procedimentos assépticos, após riscos à fluidos corporais e após contato com superfícies e objetos próximos ao paciente, tendo de $(75 \%)$ a $(88,9 \%)$ de adesáo.

É difícil mudar os hábitos, costumes, conceitos $\mathrm{e}$, principalmente, comportamentos, mas se não se investir nessa simples atitude, nada se conseguirá. Para que isso ocorra de forma efetiva, deverão ser priorizados pela comissão de controle de infecção

Tabela II - Realização da higienização das mãos segundo a ação, indicação e categoria profissional. Hospital Municipal São Vicente de Paulo - Coração de Jesus, 2011.

\begin{tabular}{|c|c|c|c|c|c|c|c|c|c|c|c|c|c|c|c|c|c|}
\hline \multirow{3}{*}{ Indicação } & \multicolumn{5}{|c|}{ Água e sabão } & \multicolumn{5}{|c|}{ Fricção álcool } & \multicolumn{5}{|c|}{ Não realizada } & \multicolumn{2}{|c|}{ Total } \\
\hline & \multicolumn{3}{|c|}{ Categoria } & \multicolumn{2}{|c|}{ Total } & \multicolumn{3}{|c|}{ Categoria } & \multicolumn{2}{|c|}{ Total } & \multicolumn{3}{|c|}{ Categoria } & \multicolumn{2}{|c|}{ Total } & \multirow[b]{2}{*}{$\mathbf{n}$} & \multirow[b]{2}{*}{$\%$} \\
\hline & $M$ & $E$ & TE & $\mathrm{n}$ & $\%$ & $M$ & $E$ & TE & $\mathrm{n}$ & $\%$ & $M$ & $E$ & TE & $n$ & $\%$ & & \\
\hline $\begin{array}{l}\text { Antes contato com } \\
\text { paciente }\end{array}$ & 01 & 01 & 01 & 03 & 11,5 & - & - & 02 & 02 & 7,7 & 16 & 01 & 04 & 21 & 80,8 & & 100 \\
\hline $\begin{array}{l}\text { Antes realizar proce- } \\
\text { dimento asséptico }\end{array}$ & 01 & - & 05 & 06 & 75 & & - & - & - & - & - & - & 02 & 02 & 25 & & 100 \\
\hline $\begin{array}{l}\text { Após riscos de } \\
\text { exposição a fluidos } \\
\text { corporais }\end{array}$ & 01 & 02 & - & 03 & 60 & - & 01 & - & 01 & 20 & - & - & 01 & 01 & 20 & & 100 \\
\hline $\begin{array}{l}\text { Após contato com } \\
\text { paciente }\end{array}$ & 01 & 03 & 03 & 07 & 18,9 & - & 03 & 05 & 08 & 21,6 & 16 & 01 & 05 & 22 & 59,5 & & 100 \\
\hline $\begin{array}{l}\text { Após contato com } \\
\text { superfície e objeto } \\
\text { próximo a paciente }\end{array}$ & - & - & 02 & 02 & 22,2 & - & 02 & 04 & 06 & 66,7 & - & - & 01 & 01 & 11,1 & & 100 \\
\hline Total & 04 & 06 & 11 & & 100 & - & 06 & 11 & 17 & 100 & 32 & 02 & 13 & 47 & 100 & 85 & 100 \\
\hline
\end{tabular}

Legenda: $M=$ médico, $E$ = enfermeiro; $T E$ = técnico em enfermagem. Fonte: Coleta de dados, 2011. 
hospitalar (CCIH) e estrutura máxima hospitalar em parceria com os pacientes, familiares e/ou visitantes, treinamentos, aulas, pesquisas, além de um trabalho de "corpo a corpo" com as equipes multidisciplinares [2].

Embora a higienização das mãos seja um procedimento simples e barato, a negligência dos profissionais da área da saúde em não realizar frequentemente essa prática é um problema mundialmente questionado. Os dados encontrados neste estudo reafirmam o que vários outros já evidenciaram, a baixa adesão dos profissionais da saúde à prática de higienização das mãos [2].

Todos os profissionais que trabalham em serviços de saúde, que mantém contato direto ou indireto com os usuários, que atuam na manipulação de medicamentos, alimentos e material estéril ou contaminado devem adotar, em sua prática, as recomendações básicas de higienização das mãos [2]

Em diversos estudos, a baixa adesão à higienização das mãos não está diretamente associada ao conhecimento teórico do ato da higienização das mãos ou da situação em que se deve realizá-la, mas sim a incorporação desse conhecimento à prática diária dos profissionais. Muitas vezes não sendo incorporada a prática do profissional em função da falta de motivação, da não concepção do risco de disseminaçáo de micro-organismo, do excesso de atividade/tarefas e da falta de materiais e/ou deficiência da estrutura física da instituição. Quanto aos aspectos relacionados à instituição, deve estar atenta a estrutura física da unidade avaliando-se a necessidades de dispensadores de álcool a 70\% devidamente instalados e abastecidos [10].

\section{Conclusão}

Tendo em vista os objetivos propostos no estudo, os resultados da pesquisa mostraram que houve baixa adesão à higienização das mãos do hospital estudado. Foram observadas 85 oportunidades, das quais 36 foram dos médicos, com adesão de apenas 4 oportunidades $(11,2 \%)$. Os enfermeiros tiveram 14 oportunidades e 12 foram aderidas $(85,8 \%)$. Os técnicos de enfermagem tiveram 35 oportunidades, e realizaram a higienização 22 vezes com $(61,8 \%)$ de adesão. A pesquisa identificou que os profissionais de saúde não higienizam as mãos de acordo com as indicaçôes, deixando de fazer nos momentos mais recomendados.

Com isso, a adesão à higienização das mãos em algumas indicaçóes não está incorporada à prática diária desses profissionais e as açóes educativas, com objetivo de aumentar a adesão dos profissionais de saúde à higienização das mãos, são necessárias e emergentes.

Portanto, é necessário avaliar a melhor estratégia de incentivo a ser abordada, pois a educação como a principal forma de divulgaçáo e multiplicação do conhecimento e informações, não tem conseguido modificar comportamentos e condutas específicas. Espera-se que as açóes educativas possibilitem a reflexão da atuaçáo de cada sujeito, propiciando a aprendizagem e modificando as práticas instituídas.

\section{Referências}

1. Felix CCP, Miyadahira AMK. Avaliação da técnica de lavagem das máos executada por alunos do Curso de Graduação em Enfermagem. Rev Esc Enferm USP 2009;43(1):139-45.

2. Primo MGB, Ribeiro LCM, Figueiredo LFS, Sirico SCA, Souza MA. Adesão à prática de higienização das mãos por profissionais de saúde de um Hospital Universitário. Rev Eletrônica Enferm 2010;12(2):266-71.

3. Rocha LA, Almeida BLF, Filho PPG. Falta de adesão à lavagem de mãos, ação irritante do uso de sabão e luvas e sua influência na microbiota qualitativa e quantitativa das mãos de enfermeiros. Newslab 2007;82:114-22.

4. Coelho MS, Arruda SC, Faria SM. Higienização das mãos como estratégia fundamental no controle de infecçóes hospitalar: um estudo quantitativo. Enfermería Global 2011;21:1-12.

5. Tipple AFV, Mendonça KM, Melo MC, Silva SAC, Pereira MS, Vieira SSL. Higienização das mãos: o ensino e a prática entre graduandos na área da saúde. Acta Sci Health Sci 2007;29(2):107-14.

6. Neves ZCP, Tipple AFV, Souza ACS, Pereira MS, Melo DS, Ferreira LR. Higienização das mãos: o impacto de estratégia de incentivo À adesão entre profissionais de saúde de uma unidade de terapia intensiva neonatal. Rev Latinoam Enferm 2006;14(4):546-52.

7. Santos FM, Gonçalves MS. Lavagem das mãos no controle da infecção hospitalar: um estudo sobre a execução da técnica. Rev Enferm Integrada 2009;2(1):1-12.

8. Brasil. Agencia Nacional de vigilância sanitária. Segurança do paciente em serviço de saúde: Higienização das mãos/Agencia Nacional de Vigilância Sanitária. Brasília: Anvisa 2009.105p.

9. Mendonça AP, Fernandes MSC, Azevedo JMR, Silveira WCR, Souza ACS. Lavagem das mãos: adesão dos profissionais de saúde em uma unidade de terapia intensiva neonatal. Acta Scientiarum Health Sciences 2003;25(2):147-53.

10. Barbosa LR. Correlação entre métodos de mensuração da adesão a higienização das mãos em unidade de terapia intensiva neonatal [tese]. São Paulo: Faculdade de Saúde Pública da USP; 2010.

11. Oliveira AC, Cardoso CS, Mascarenhas D. Precauçóes de contato em Unidade de Terapia Intensiva: fatores facilitadores e dificultadores para adesão dos profissionais. Rev Esc Enferm USP 2010;44(1):161-65. 